\title{
Japan flirts modestly with international review
}

Tokyo. The international scrutiny of Japanese laboratories seems to be catching on. Earlier this year, the University of Tokyo opened its physics department to external review (Nature 362, 387; 1993). Now, the Institute of Physical and Chemical Research (RIKEN) is following suit. Next week, an international team will visit the laboratory complex to evaluate RIKEN's management and research.

It is not surprising that RIKEN, located in the northwest outskirts of Tokyo, should be the first government-supported laboratory to risk external evaluation. A semiautonomous corporation supported primarily by the Science and Technology Agency, it is one of the most dynamic and flexible of Japan's research institutes. In recent years, for example, it has been an eager (and imaginative) employer of overseas researchers.

RIKEN's research covers a broad range of science and technology, from the physical sciences and engineering to biology and the medical sciences. It has a branch for life science research at Tsukuba and (with the Japan Atomic Energy Research Institute) is building the world's most powerful synchrotron at $8 \mathrm{Ge}$ in Harima science garden city, west of Osaka. RIKEN also recently opened a laboratory for photodynamic research at Sendai, north of Tokyo, and another at Nagoya for research on biomimetic control as part of its Frontier Research Programme, some of whose project leaders are from overseas.

RIKEN plans to go further in its own evaluation than the University of Tokyo, which has not yet decided whether the external review of physics will be repeated, let alone extended to other departments. Before knowing the outcome of the first external review, RIKEN says the process will be repeated every two years.

The evaluation will be done by what is called the RIKEN Advisory Council (RAC), whose 15 members include Nobel prizewinner Heinrich Rohrer of IBM's research laboratory in Switzerland, Lord Adrian, master of Pembroke College at the University of Cambridge in Britain and Thomas Everhart, president of the California Institute of Technology in the United States. They are joined by scientists from Japan, including Setsuro Ebashi, former director-general of the three Okazaki national research institutes, Michiyuki Uenohara, a former senior executive of NEC Corporation, and Tokindo Okada, emeritus professor of Kyoto University.

The council will be briefed on RIKEN next Monday [21 June], after which five subcomittees will spend three days examining different laboratories. Its report will first go to RIKEN's president, Minoru Oda, who has keenly supported the idea of an external review, first put forward in 1990 by George Clarke of the Massachusetts Institute of Technology.

RIKEN is by now well used to evaluation. Since 1983, there has been a regular cycle of reviews by teams of four outsiders, three from Japanese universities and national laboratories and one from industry. Each laboratory is dealt with every seven years or so, and the results often stimulate action, even reorganization. But RAC will evaluate the research programme as a whole as well as the management of RIKEN, the policy of the board of directors included. With the exception of the one-off review of Tokyo University's physics department, procedures of this kind are unheard of at other Japanese government research facilities.

But other national laboratories are soon expected to follow RIKEN. The Agency of

\section{China's science budget outgrows economy}

Beijing. China will this year increase spending on science by more than 10 per cent in recognition of its potential contribution to the national economy, the fastest growing in the world.

The 1993 budget endorsed last month by the Eighth National People's Congress allocates almost 20 billion yuan (US\$3.5 billion) for science and technology and 60 billion yuan for education. Despite a projected deficit of 3.5 billion yuan, the budget assumes an annual growth rate of 9 per cent. (Other sources estimate an increase of as much as 13 per cent.)

Science is a major focus of the budget. Although spending figures on individual projects are regarded as a secret (see Nature 362, 685; 1993), Zou Jia-Ha, vice-premier and director of the State Planning Commission, mentioned five areas where the government is increasing its investment in sci-

\section{3 science budget}

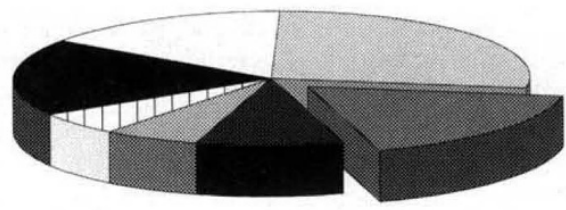

Science, health \& education
National defence Agriculture Industry
Capital construction Price \& debit subsidies Admin. \& other costs ence in a speech to the congress.

The government has selected $600-800$ projects, many involving microelectronics, where it expects to translate basic research into commercial products. At the same time, Zou said, existing state initiatives on applied technology such as the Climbing Programme, the 863 High-Technology Programme, the Torch Programme and the Sparkle Programme will be fully funded. The government has also proposed building a network of state laboratories, ecological facilities and engineering centres, and has promised to make existing laboratories and research centres more efficient. Finally, undergraduate enrolment will be increased, as will the number of universities.

Although the increased budget is welcome, some regard the increases as insufficient. Hu Jian, an official at the National Natural Sciences Foundation, China's main source of funds for basic science, says that an increase in its budget of 20 per cent a year over the next three years will still not satisfy demand. In education, deputies to the recent People's Congress demanded that the government pay teachers on time salaries are often withheld for as long as six months.

The government says the research will strengthen the economy, "to make research, trade and economy all in one". This approach, underlined by the recent forced realignment of 70 per cent of the scientific staff at the Chinese Academy of Sciences towards applied research, naturally moderates the enthusiasm of Chinese scientists for the news of more money for science.

You Qin Li 